\title{
Protein Profiling of Helicobacter pylori-Associated Gastric Cancer
}

Guodong Lian, * Chengguo Wei, ${ }^{\dagger}$ Daguang Wang, ${ }^{*}$ Miao Cui, ${ }^{\ddagger}$ Zhiqing Wang, ${ }^{\S}$ Xiufen Liu,, Wei Li, ${ }^{*}$ Lei Wang, * Qingfeng Wang, * David Y. Zhang, Jian Suo, ${ }^{*}$ and Fei Ye

From the Departments of Gastrointestinal Surgery* and Ophthalmology, "First Hospital of Jilin University, Changchun, China; the Departments of Medicine Bioinformatics Core ${ }^{\dagger}$ and Pathology, ${ }^{\ddagger}$ Mount Sinai School of Medicine, New York, New York; and the Department of Gastroenterology, ${ }^{\S}$ Nanfang Hospital, Southern Medical University, Guangzhou, China

\author{
Accepted for publication \\ January 6, 2014. \\ Address correspondence to Jian \\ Suo, M.D., Ph.D., Department \\ of Gastrointestinal Surgery, \\ First Hospital of Jilin Univer- \\ sity, Changchun, Jilin 130021, \\ China; or Fei Ye, PhD., Depart- \\ ment of Pathology, Mount Sinai \\ School of Medicine, New York, \\ NY 10029. E-mail: suojian42@ \\ gmail.com or fei.ye@mssm.edu.
}

\begin{abstract}
Helicobacter pylori infection is an initiating factor in the development of gastric cancer. Gastric cancer can be divided into two groups on the basis of $H$. pylori serological status; seropositive $H$. pylori status predicts favorable prognosis in patients with gastric cancer. By using the protein pathway array, we identified 20 differentially expressed proteins in primary gastric cancer tissues between the $H$. pyloriseropositive and $\mathrm{H}$. pylori-seronegative groups. Our results indicate that both brassinosteroid insensitive 1 -associated kinase 1 and calpastatin are favorable prognostic factors in $H$. pylori-seropositive gastric cancer patients. In contrast, dachshund homolog 1 is a favorable prognostic factor in $H$. pylori-seronegative gastric cancer patients. Different signaling pathways were found to be altered between $H$. pylori-seropositive and $H$. pylori-seronegative gastric cancer, which may account for the different tumorigenesis and outcomes between these two subsets of patients. (Am J Pathol 2014, 184: 1343-1354; http://dx.doi.org/10.1016/j.ajpath.2014.01.027)
\end{abstract}

More than $20 \%$ of cancers have been causally linked to human pathogens. ${ }^{1}$ Helicobacter pylori was declared as a class I carcinogen by the International Agency for Research on Cancer in 1994, and it colonizes $>50 \%$ of the world's population. ${ }^{2}$ Some of the infected individuals progress through a series of pathological changes, from chronic gastritis to atrophy, metaplasia, and dysplasia; finally, approximately $1 \%$ of the infected individuals are predicted to develop gastric cancer. ${ }^{3,4}$ Approximately $90 \%$ of gastric cancer was usually diagnosed at an advanced stage, with a 5-year survival rate of $20 \%$. In addition, gastric cancer remains the fourth most common cancer and the second most common cause of cancer-related death worldwide, responsible for approximately $10 \%$ of all deaths from cancer. ${ }^{4-6}$

Numerous epidemiological surveys support a positive association between $H$. pylori infection and the development of gastric cancer, in which $65 \%$ of gastric cancers could be attributed to $H$. pylori infection ${ }^{7,8}$; others could be attributed to environment, dietary habit, and hereditary factors. Adenocarcinoma is the most common histological type of gastric cancer, which can be further classified into intestinal and diffuse types. H. pylori-associated gastric cancer is predominantly the intestinal type, mostly involved in noncardial areas. ${ }^{9}$ Clinically, several studies reported differences in relapse-free and overall survival between $H$. pyloriseropositive and $H$. pylori-seronegative gastric cancer patients. ${ }^{10-13}$ These studies showed that patients with seropositive $H$. pylori status had a favorable prognosis compared with those who had a seronegative status.

Previous cell and animal experiments explored the cellular and molecular mechanisms of $H$. pylori-induced gastric cancer. $^{14-17}$ Along with $H$. pylori carcinogenic effects, the inflammatory response to $H$. pylori, which is highly variable, contributes to lowering the threshold of malignant transformation. ${ }^{18}$ For example, H. pylori up-regulates activationinduced cytidine deaminase protein, which could induce mutagenesis in DNA sequences of the gastric epithelium. ${ }^{19}$ Knowledge of the precise signaling pathways driving cell transformation in $H$. pylori-induced gastric cancer is incomplete. In this study, we screened the protein expression

Supported by National Natural Science Foundation of China grant 81372295. This study was performed in partial fulfillment of the requirements for a Ph.D. degree (G.L.).

Disclosures: None declared. 
profiles of adenocarcinoma from gastric cancer patients with positive and negative $H$. pylori serological results using the high-throughput protein pathway array (PPA). ${ }^{20} \mathrm{We}$ identified $>20$ differentially expressed proteins between these two subsets. Several proteins correlate with favorable relapse-free and overall survivals in $H$. pylori-seropositive gastric cancer patients.

\section{Materials and Methods}

\section{Patients and Follow-Up}

We selected 120 consecutive patients who had undergone curative resection for primary gastric adenocarcinoma between August 2008 and June 2011 at the First Hospital of Jilin University (Jilin, China). Nineteen patients were excluded from the study because they had $\mathrm{R} 1$ resection $(n=2$, no gross residue tumor but margins were microscopically positive for tumor), $\mathrm{R} 2$ resection ( $n=2$, with gross residual tumor), lung metastasis $(n=5)$, or extensive abdominal metastases $(n=10)$. Thus, 101 patients were included in this study. The research protocol was approved by the ethics committee of Jilin University's Institutional Ethical Review Boards, and written informed consent was obtained. Subtotal or total gastrectomy (eight patients underwent gastrectomy combining partial liver resection for localized superficial liver metastasis) and D2 lymph node dissection (ie, radical gastrectomy with level 2 extended lymphadenectomy) were performed in all patients according to Japanese gastric cancer treatment guidelines. Tumor localization, size, and depth of tumor invasion ( $\mathrm{T}$ stage), lymph node metastasis ( $\mathrm{N}$ stage), and histological grading were recorded. According to their clinical and histopathological results, comorbidity, and ability to tolerate treatment, 67 patients underwent adjuvant chemotherapy with fluorouracil, cisplatin, and folic acid. Of these 67 patients, 7 underwent preoperative and postoperative chemotherapy and 60 only underwent postoperative chemotherapy. The demographics and clinicopathological characteristics of the patients are summarized in Table 1. The TNM stage of the tumor was defined according to the American Joint Committee on Cancer (AJCC) Cancer Staging Manual, 7th Edition. ${ }^{21}$

Patients were followed up in our hospital by the staff in the Department of Gastrointestinal Surgery. Within the first year after surgery, the patients were followed up on every 3 months, and physical examination, routine blood tumor marker test, and abdominal ultrasonography were performed at each visit. Abdominal computed tomographic scanning and upper gastrointestinal tract endoscopy were performed every 6 months. For the subsequent 3 years, patients were followed up every 6 months and underwent upper endoscopy and abdominal computed tomographic scanning every 12 months. Relapse was defined as local recurrence or metastasis at distant sites. Relapse-free survival time was calculated from the date of surgery to the day of detection of local recurrence or metastasis. Overall survival time was calculated from the date of surgery to the last day of follow-up or the date of death.

\section{Tissue and Serum Sampling}

Tissue samples were dissected and frozen in liquid nitrogen within 30 minutes of removal after immediate pathological examination. The $3 \times 3 \times 5 \mathrm{~mm}^{3}$ tumor tissues were resected from the peripheral viable tumor, to avoid necrotic tissue and contamination of normal tissue. Serum samples were collected 1 day before surgery through venipuncture. After centrifugation, the serum samples were stored at $-70^{\circ} \mathrm{C}$ until $H$. pylori serological status was tested.

\section{ELISA Assay}

To define the H. pylori serological status of the patients, both H. pylori-IgG (Diamedix Corporation, Miami, FL) and cytotoxin-associated antigen A (CagA; CUSABIO, Wuhan, China) were tested by enzyme-linked immunosorbent assay (ELISA). The $H$. pylori-IgG antibody titers were calculated on the basis of OD readings at $450 \mathrm{~nm}$, according to the manufacturer's protocol, and an OD value greater than the threshold value of 0.280 (mean absorbance values of three times the cutoff calibrator) was considered as seropositive for H. pylori-IgG. The CagA antibody titers were calculated on the basis of OD value at a $450-\mathrm{nm}$ wavelength, and $\geq 2.1$ of the ratio of sample OD/negative control OD was considered as positive; $<2.1$ of the ratio of sample $\mathrm{OD} /$ negative control OD was considered as negative according to manufacturer's protocol. Either $H$. pylori-IgG positive or CagA IgG positive was considered as seropositive for $\mathrm{H}$. pylori, suggesting that the patient was previously infected with $H$. pylori. All assays were performed without knowledge of the clinicopathological features of the subjects.

\section{PPA Analysis}

Total protein was extracted from each sample, as previously described. ${ }^{22}$ A total of $1 \mathrm{~mL}$ of $1 \times$ lysis buffer (Cell Signaling Technology, Danvers, MA), with $1 \times$ protease inhibitor cocktail (Roche Applied Science, Indianapolis, IN) and $1 \times$ phosphatase inhibitor cocktail (Roche Applied Science), was added to each tissue sample, and the lysate was sonicated three times for 15 seconds each time on ice water, then centrifuged at $35,000 \times g$ for 30 minutes at $4^{\circ} \mathrm{C}$. The protein concentration was determined using the BCA Protein Assay kit (Pierce, Rockford, IL). Protein lysate $(300 \mu \mathrm{g})$ was loaded in one well across the entire width of $10 \%$ SDS polyacrylamide and separated by electrophoresis. ${ }^{23}$ After electrophoresis, the proteins were transferred electrophoretically to a nitrocellulose membrane (Bio-Rad, Hercules, CA). Each sample was transferred to three nitrocellulose membranes; the membrane was then blocked for 1 hour with blocking buffer, including $3 \%$ bovine serum albumin in $1 \times$ Tris-buffered saline with Tween 20 containing $20 \mathrm{mmol} / \mathrm{L}$ Tris- $\mathrm{HCl}$ ( $\mathrm{pH} 7.5$ ), $100 \mathrm{mmol} / \mathrm{L} \mathrm{NaCl}$, and $0.1 \%$ Tween 20 (Fisher BioReagents, Pittsburgh, PA). Next, the membrane was clamped on a Western blotting manifold (Mini-PROTEAN II Multiscreen 
Table 1 Clinicopathological Characteristics of 101 Gastric Adenocarcinomas on the Basis of $H$. pylori Serological Status

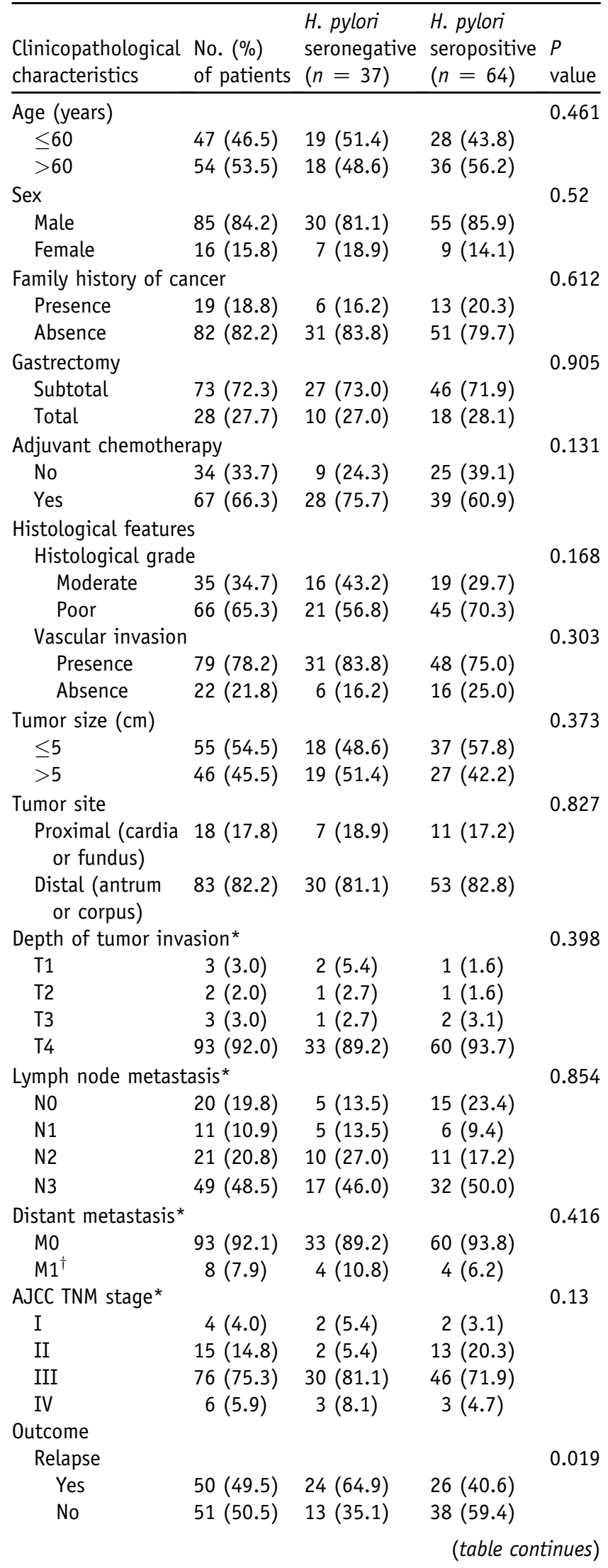

Table 1 (continued)

\begin{tabular}{|c|c|c|c|c|}
\hline $\begin{array}{l}\text { Clinicopathological } \\
\text { characteristics }\end{array}$ & $\begin{array}{l}\text { No. }(\%) \\
\text { of patients }\end{array}$ & $\begin{array}{l}\text { H. pylori } \\
\text { seronegative } \\
(n=37)\end{array}$ & $\begin{array}{l}\text { H. pylori } \\
\text { seropositive } \\
(n=64)\end{array}$ & $\begin{array}{l}P \\
\text { value }\end{array}$ \\
\hline \multicolumn{2}{|c|}{ Status at last follow-up } & & & 0.037 \\
\hline Deceased & $49(48.5)$ & $23(62.2)$ & $26(40.6)$ & \\
\hline Living & $52(51.5)$ & $14(37.8)$ & $38(59.4)$ & \\
\hline
\end{tabular}

A $\chi^{2}$ test was used to compare all variables, except liver metastasis (Fisher's exact test) and T, N, and TNM stages (Spearman test). $P$ refers to differences in proportions of variables between different groups. ${ }^{*}$ According to the AJCC Cancer Staging Manual, 7th Edition. ${ }^{21}$

${ }^{\dagger}$ One isolated metastasis to superficial liver.

apparatus; Bio-Rad), which isolates 20 channels across the membrane. The multiplex immunoblot was performed using a total of 286 protein-specific or phosphorylation sitespecific antibodies (Table 2). All phosphorylation statespecific antibodies were obtained from Cell Signaling Technology, except the following antibodies: $p$-protein kinase $\mathrm{C} \alpha$ (Ser657) was purchased from Upstate Biotech (Lake Placid, $\mathrm{NY}$ ); $p$-Met (Tyr1234), $p$-c-Jun kinase (G-7), and $p$-focal adhesion kinase (Tyr397) were purchased from Santa Cruz Biotechnology (Santa Cruz, CA).

All non-phosphorylated antibodies were obtained from Santa Cruz Biotechnology, except the following antibodies: Stat1, human epidermal growth factor receptor 2/ErbB2, $\beta$-catenin, $p 44 / 42$ mitogen-activated protein kinase [MAPK; extracellular signal-regulated kinase (Erk) 1/2], Akt, Notch4, eukaryotic initiation factor 4B, NF- $\mathrm{B}$ p50, cAMPresponsive element binding, estrogen receptor $\alpha, \mathrm{Bcl}-\mathrm{xL}$, ribosome inactivating protein, aurora A/aurora/Ipl1-related kinase, matrix metalloproteinase-9, and snail (Cell Signaling Technology); X-linked inhibitor of apoptosis and glutamine synthetase (BD Biosciences, San Jose, CA); transforming growth factor (TGF)- $\beta$ (R\&D Systems, Minneapolis, MN); Hsp90 (ENZO Life Sciences, Farmingdale, NY); hypoxiainducible factor- $2 \alpha$ (Novus Biologicals, Littleton, CO); cytokeratin 18 (Dako Corporation, Carpinteria, CA); fumarylacetoacetate hydrolase (Proteintech Group, Chicago, IL); keratin 10 (Covance Research Products, Berkeley, CA); and $\mathrm{G}$ protein of vesicular stomatitis virus (Abcam Corporation, Cambridge, MA). Three membranes were generated for each sample, each membrane was blotted with three sets of antibodies, and a total of nine sets of antibodies were used for each sample. For the primary antibodies, a mixture of one or two antibodies in the blocking buffer was added to each channel and then incubated at $4^{\circ} \mathrm{C}$ overnight. The membrane was then washed with $1 \times$ TBS and $1 \times$ Tris-buffered saline with Tween 20 and was further incubated with secondary anti-rabbit (Bio-Rad), anti-mouse (Bio-Rad), or anti-goat (Santa Cruz Biotechnology) antibody conjugated with horseradish peroxidase for 1 hour at room temperature. The membrane was developed with chemiluminescence substrate (Immun-Star HRP Peroxide Buffer/Immun-Star HRP Luminol 
Table 2 List of Antibody Targets Included in the PPA

\begin{tabular}{|c|c|c|c|c|}
\hline \multicolumn{5}{|c|}{ Antibody targets specific for phosphorylation } \\
\hline p-AKT (Ser473) & p-ERK5 (Thr218/Tyr220) & $\begin{array}{l}p \text {-P44/42 MAPK (Erk1/2) } \\
(\text { Thr202/Tyr204)* }\end{array}$ & $\begin{array}{l}p-\mathrm{PKC} \alpha / \beta \text { II } \\
\quad(\text { Thr638/641) }\end{array}$ & p-STAT 3 (Ser727)* \\
\hline$p$ - $\beta$-Catenin (Ser33/37/Thr41) & p-FAK (Tyr397) & $p$-P53 (Ser392) & p-PKC $\delta$ (Thr505) & p-STAT5 (Tyr694) \\
\hline$p$-c-Jun (Ser73) & $p$-JNK(G-7) & $p$-P90RSK (Ser380) & $p-\mathrm{Rb}(\operatorname{Ser} 780)$ & \\
\hline$p$-CREB (Ser133) & p-Met (Tyr1234) & p-PDK1 (Ser241) & $p-\mathrm{Rb}(\operatorname{Ser} 807 / 811)$ & \\
\hline $14-3-3 \beta$ & cSHMT & HER2/ErbB2 & MMP-13 & Rap1 \\
\hline$\alpha$-Tubulin & CTGF & HES1 & MSR & Reg IV \\
\hline ADAM8 & CTLA-4 & HGF & MTA1 & RHAMM \\
\hline ADAM10 & CUL-1 & HIF-1 $\alpha$ & MTHFD1 & RhoA \\
\hline ADH & CX3CR1 & HIF- $2 \alpha$ & MTHFD2 & Ribosomal protein L6 \\
\hline ASCL1 & Cytokeratin $18^{*}$ & HoxC11 & NF-кB p50 & Smad4 \\
\hline ASC-R & Cytokeratin 19 & H-Ras & NF- $\kappa$ B p52 & Smad7 \\
\hline ATF-1 & DACH1* & HSL & NF-кB p65 & Snail \\
\hline Aurora A/AIK & DARPP-32 & HSP 27 & NHERF-2 & S0D-1 \\
\hline Autotaxin & DDB2 & HSP70* & Nkx-3.1 & SPAK \\
\hline Axin & DHFR & Hsp90 & $\mathrm{nm} 23-\mathrm{H} 1 / 2 / 3$ & SRC-1 \\
\hline$\beta 3$-Tubulin & Dnmt1 & ICAM-1 & NMT1 & Stat1 \\
\hline$\beta$-Catenin * & DPYD* & ID0 & NOS2 & Stat3 \\
\hline Bad & DRG1 & IFN- $\gamma$ & Notch4 & SUGT1 \\
\hline Bak* & $\mathrm{E} 2 \mathrm{~A}$ & IGFBP5 & NQ01 & Survivin \\
\hline Bax & E2F1 & IGF-Ir $\beta$ & ODC & Syk \\
\hline Calpastatin* & EphB2 & Integrin $\alpha 4$ & P504S & TIP30 \\
\hline Calretinin & Epo & IRF-1 & p53 & TIRAP \\
\hline CaMKK $\alpha$ & ERCC1 & ITF & p63 & TNF-R2 \\
\hline CARD12 & $\mathrm{ER} \alpha$ & Jagged1 & p73 & TNF $\alpha$ \\
\hline Caspase-1 & $E R \beta$ & JAK2 & Pannexin-1 & tPA \\
\hline Cathepsin B* & E-selectin & JNK1 & Patched & TRAF6 \\
\hline CD10 & Factor XIII B & KAI 1 & Pax-2 & TS \\
\hline CD33 & $\mathrm{FAH}$ & Keratin 10 & PC2 & tsg101 \\
\hline Cdc2 p34* & FAS & KiSS-1 & P-cadherin & TTF-1 \\
\hline Cdc25B & FEN-1 & KLF6 & PCNA & Twist \\
\hline Cdc25C & FGF-8 & K-Ras & PDEF & Tyro3 \\
\hline Cdc42 & FGFR-4 & LKB1 & PEDF & uPA \\
\hline Cdk2 & FKHR $^{*}$ & LSD1 & PERK & UPAR \\
\hline Cdk4 & FLIPS/L & L-selectin* & PKC $\alpha$ & VAP-1 \\
\hline Cdk6 & Flt-3/Flk-2 & Lyn & $\mathrm{PKC} \varepsilon$ & V-ATPase H \\
\hline$C d \times 2$ & FoXM1 & Maspin & Plk & VCAM-1 \\
\hline c-Fms/CSF-1R & $\mathrm{FT} \alpha$ & MAT II $\beta$ & PRL-3 & VEGF \\
\hline Chk1 & FUS/TLS & MDM2 & PSCA & Vimentin \\
\hline C-IAP2* & Fusin & Mesothelin & PSM & VSV-G \\
\hline CKR-7 & Galectin-3 & MetAP-2 & PSTPIP1 & Wnt-1 \\
\hline Clusterin & GLP-1R & MetRS & PTEN & WT1 \\
\hline
\end{tabular}


Table 2 (continued)

Antibody targets specific for phosphorylation

\begin{tabular}{|c|c|c|c|c|}
\hline COL1A2 & Glutamine synthetase & MGr1-Ag & Rab 7 & XIAP \\
\hline Connexin 43 & GSTP1 & MMP-2 & Raf-B & YB-1 \\
\hline Cox-2 & HCAM & MMP-7 & RAGE & \\
\hline CREB & HDAC1 & MMP-9 & RANKL & \\
\hline
\end{tabular}

Antibodies with detectable expression in either H. pylori seropositive or seronegative gastric cancer patients are in bold. $\beta$-Actin and glyceraldehyde-3phosphate dehydrogenase served as internal control.

*Differentially expressed proteins between $H$. pylori seropositive and seronegative gastric cancer patients.

Enhancer; Bio-Rad), and chemiluminescent signals were captured using the ChemiDoc XRS System (Bio-Rad). The same membrane was then stripped off using stripping buffer (Restore Western blot stripping buffer; Thermo Scientific, Rockford, IL) and then used to detect another set of primary antibodies, as described above.

For PPA data analysis, the signal of each protein was determined by densitometric scanning (Quantity One software package version 4.6.2; Bio-Rad), and the background was locally subtracted from raw protein signal. Then, the background-subtracted intensity was normalized by the global median subtraction method to reduce variation among different experiments. In detail, the intensity of each protein from each sample was divided by total intensities of all proteins from the same sample, and then multiplied by average intensities of all proteins in all samples. ${ }^{22}$

\section{Statistical Analysis}

A $\chi^{2}$ Test was used to assess the association between H. pylori status and other clinicopathological variables. A Fisher's exact test was used to analyze the effect of distant metastasis. A Spearman test was used to analyze the association between $H$. pylori status and $\mathrm{T}$ stage, $\mathrm{N}$ stage, and TNM stage. The Significant Analysis of Microarray tool (http://www-stat.stanford.edu/ tibs/SAM, last accessed June 20, 2013, registration required) was used to identify the proteins differentially expressed between $H$. pylori-seropositive and $H$. pylori-seronegative gastric cancer tissues. $\mathrm{K}$-fold cross validation ( $\mathrm{K}=10$ ) was used to select proteins with a great discriminating power to distinguish these two groups. K-fold cross validation and unsupervised hierarchical clustering analysis were performed using BRB Array Tools software version 3.3.0 (http://linus.nci.nih.gov/BRBArrayTools.html, last accessed June 20, 2013). SPSS version 17.0 software (SPSS Inc., Chicago, IL) was used for Cox proportional hazards regression analysis to correlate the PPA data with the clinical data (ie, TNM and survival), as well as log-rank test in Kaplan-Meier survival analyses in assessing the effect of variables on relapse-free survival and overall survival. For all statistical tests, an $\alpha$ level of 0.05 was applied.

\section{Signaling Network Analysis}

The discriminating genes of the corresponding proteins identified by PPA were imported for network analysis by
Ingenuity Pathway Analysis (IPA), version 9.0 (Ingenuity Systems Inc., Redwood City, CA). IPA uses the Ingenuity Knowledge Base as a reference set and identifies local networks that are particularly enriched for the input genes by computational algorithms. Furthermore, IPA uses a Fisher's exact test to determine which pathways (ie, canonical pathways, toxicity pathways, and biological functions) are significantly linked to the input gene set compared with the whole Ingenuity knowledge base.

\section{Results}

\section{H. pylori Serological Status}

Overall, 63.4\% (64 of 101) of patients were seropositive for H. pylori (combined H. pylori-IgG and CagA serum ELISA results $^{24}$ ) at the time of surgery. The patients' demographics and clinicopathological characteristics are summarized in Table 1 . The mean age of the patients was 60.6 years, and the ratio between males and females with gastric cancer was 5.3:1. Of all patients, $18.8 \%$ (19 of 101) had a family cancer history (all malignancies); among them, 20.3\% (13 of 64) were seropositive and $16.2 \%$ (6 of 37) were seronegative for $H$. pylori. In all gastric carcinoma patients, $17.8 \%$ (18 of 101) were located at the cardia or fundus, $59.4 \%$ (60 of 101) at the antrum, and $22.8 \%$ (23 of 101) at the corpus. The ratio between distal (antrum or corpus) and proximal (cardia or fundus) gastric carcinoma was 4.6:1. Eight patients had partial liver resection for isolated metastatic tumor in addition to D2 gastrectomy. No significant difference in the tumor site distribution and histological grade $(P>0.10)$ between $H$. pylori-seropositive and $H$. pylori-negative patients was observed.

\section{H. pylori Status Was an Independent Prognostic Factor}

Median follow-up of the patients was 30.7 months (range, 2.7 to 60 months); at last follow-up, 57 patients had relapsed (45 with local recurrence and 12 with metastases at distant sites). Twenty-six patients with negative $H$. pylori serological results relapsed $[70.3 \%(26 / 37)]$ compared with 31 with positive $H$. pylori serological results [48.4\% (31/64)] $(P=0.026)$. Relapse-free survival was 32.9 months $(95 \%$ CI, 28.5-37.3 months) in the H. pylori-seropositive group, compared with 22.0 months (95\% CI, 16.5-27.5 months) in the H. pylori-seronegative group (log-rank $P=0.003)$. 
Kaplan-Meier survival analyses showed that $H$. pylori serological status significantly correlated with relapse-free and overall survival rates in gastric cancer patients (ie, H. pylori seropositive correlated with favorable relapse-free and overall survival rates; log-rank $P=0.026$ and $P=0.017$, respectively) (Figure 1). Univariate analyses indicated an association between relapse-free survival and tumor size [hazard ratio (HR), 1.931; 95\% CI, 1.1-3.4; $P=0.021$ ], lymph node metastasis (HR, 1.682; 95\% CI, 1.248-2.266; $P=0.001$ ), distant metastasis (HR, 5.363; 95\% CI, 2.248-12.797; $P=0.000$ ), TNM stage (HR, 3.827; 95\% CI, 1.974-7.419; $P=0.000$ ), and seronegative $H . p y$ lori status (HR, 2.155; 95\% CI, 1.235-3.759; $P=0.007$ ) (Supplemental Table S1). Multivariate analyses indicated that H. pylori-seronegative status, lymph node metastasis, distant metastasis, and family history of cancer were independent prognostic factors for unfavorable relapse-free survival and overall survival (Table 3). Mean overall survival was 34.5 months (95\% CI, 30.2-38.9 months) in gastric cancer patients seropositive for $H$. pylori, compared with 24.2 months (95\% CI, 18.9-29.5 months) in patients seronegative for $H$. pylori (log-rank $P=0.004$ ). Seronegative $H$. pylori status, lymph node metastasis, distant metastasis, and family history of cancer were independent prognostic factors for poor overall survival (Table 3 and Supplemental Table S2).

Identification of Differentially Expressed Proteins and Phosphoproteins between $H$. pylori-Seropositive and H. pylori-Seronegative Gastric Cancer

Gastric cancer tissues from 101 patients $(64 \mathrm{H}$. pylori seropositive and $37 \mathrm{H}$. pylori seronegative) were used to screen the differently expressed proteins using PPA. Among 286 protein-specific or phosphorylation sitespecific proteins tested, 137 were detected in cancer tissues. The Significant Analysis of Microarray tool analysis (on the basis of 1000 permutation analysis and a 5\% falsediscovery rate) showed that 20 of these proteins/phosphoproteins had a significant difference $(\mathrm{q}<5 \%)$ between $H$. pylori-seropositive and $H$. pylori-seronegative groups (Supplemental Table S3). Among them, 13 proteins and phosphoproteins were up-regulated in $H$. pyloriseropositive gastric cancer tissues, including BAK1, calpain 2, p-P44/42 MAPK, calpastatin, $p$-glycogen synthetase kinase (GSK) 3, c-IAP2, DACH1, BCL-xL, HSP70, $\beta$-catenin, $p$-STAT3, FKHR, and E-cadherin. Seven proteins were down-regulated in $H$. pylori-seropositive gastric cancer tissues, including DPYD, P27, cathepsin B, cytokeratin 18, TGF- $\beta, \mathrm{CDC} 2$, and L-selectin. We further performed supervised $\mathrm{K}$-fold cross validation $(\mathrm{K}=10)$ analysis using a support vector machine, and 17 proteins (BAK1, calpain 2, p-P44/42 MAPK, calpastatin, BCL-xL, $p$-GSK $3 \beta$, c-IAP2, DACH1, HSP70, $\beta$-catenin, $p$-STAT3, FKHR, DPYD, P27, cathepsin B, E-cadherin, and CDC2) were selected to separate gastric cancer of the $H$. pyloriseropositive group from the $H$. pylori-seronegative group, with a $92 \%$ correct rate, $98.4 \%$ sensitivity, and $81.1 \%$ specificity. To visualize the relative expression pattern of the 17 proteins in relation to $H$. pylori status, a two-way hierarchical clustering analysis was performed and the results showed a clear separation of $H$. pylori-seropositive from H. pylori-seronegative tissues (Figure 2).

An additional 36 gastric cancer samples were obtained to validate the expression patterns of BAK1, calpastatin, and DACH1 between $H$. pylori-seropositive $(n=20)$ and $H$. pylori-seronegative $(n=16)$ samples using Western blot analysis (Supplemental Figure S1, A-D). The expression level of these three proteins was higher in $H$. pylori-seropositive samples than in seronegative cases, which further confirmed our initial PPA findings (Figure 2). To determine the heterogeneity of protein expression within the tumor, we also obtained an additional six fresh gastric cancer tissues from six patients using Western blot analysis. For each cancer tissue, three samples were collected from the 4-, 8-, and 12-o'clock positions. Twelve antibodies were tested on these 18 samples (Supplemental Figure S2, A and B), and the results showed that protein expression level among three different sites of each tumor was relatively consistent.

\section{Difference in Signaling Pathway and Connectivity Network between $\mathrm{H}$. pylori-Seropositive and H. pylori-Seronegative Patients}

To understand how these 20 differentially expressed proteins affect the signaling pathways, these proteins were input into IPA version 9.0, which is a computer-based program for analysis of protein-protein and protein-gene interactions. The top 20 canonical signaling pathways dysregulated in $H$. pylori-seropositive gastric cancer are shown in Figure 3A. H. pylori likely interacts with the ERK/MAPK signaling pathway and the $\beta$-catenin signaling pathway (Figure 3, B and C). The dysregulation of these proteins in H. pylori-seropositive patients likely leads to increased proliferation and survival, as well as reduced ability of cell death, a hallmark of malignancy.
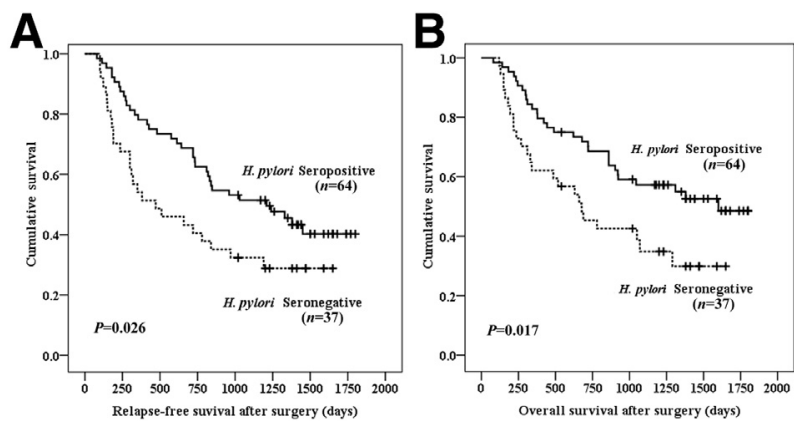

Figure 1 Kaplan-Meier survival analysis of relapse-free survival (A) and overall survival (B) between $H$. pylori seropositive and seronegative gastric cancer patients. $P$ value determined by log-rank test. 
Table 3 Independent Predictive Factors for Relapse-Free and Overall Survival on the Basis of Multivariate Analysis of 101 Patients with Gastric Cancer

\begin{tabular}{|c|c|c|c|c|}
\hline \multirow[b]{2}{*}{ Variables } & \multicolumn{2}{|l|}{$\mathrm{HR}(95 \% \mathrm{CI})$} & \multicolumn{2}{|l|}{$P$ values } \\
\hline & Relapse-free survival & Overall survival & Relapse-free survival & Overall survival \\
\hline Lymph node metastasis & $1.84(1.32-2.57)$ & $1.76(1.27-2.43)$ & 0.000 & 0.001 \\
\hline H. pylori seronegative & $2.42(1.37-4.24)$ & $2.06(1.16-3.66)$ & 0.002 & 0.013 \\
\hline Family history of cancer & $2.25(1.17-4.33)$ & $2.30(1.19-4.44)$ & 0.015 & 0.013 \\
\hline
\end{tabular}

\section{Correlation between Protein Expression and Relapse-Free Survival and Overall Survival}

To understand the correlation of these proteins with relapsefree and overall survival, Kaplan-Meier and log-rank survival analysis was conducted. The results showed that low expression of BAK1 and calpastatin correlated with a poor survival in the gastric cancer patients with $H$. pylori-seropositive test results (log rank, $P=0.024$ for relapse-free survival and $P=0.005$ for overall survival, and $P=0.003$ for relapse-free survival and $P=0.006$ for overall survival, respectively), but not in the gastric cancer patients with $H$. pylori-seronegative test results (Figures 4 and 5). In contrast, the low expression of DACH1 correlated with a poor survival in gastric cancer patients seronegative for $H$. pylori (log rank, $P=0.000$ for relapse-free survival and $P=0.001$ for overall survival), but not in patients with $H$. pylori-seropositive test results (Figures 4 and 5). Furthermore, BAK1, calpastatin, and DACH1 had a high level of expression in gastric cancer tumors with $H$. pylori-seropositive test results and correlated with the better outcome in the $H$. pylori-seropositive gastric cancer patients.

A univariate Cox proportional hazard regression analysis was performed on clinicopathological parameters and the 30 differentially expressed proteins in $H$. pylori-seropositive tissues. Lymph node metastasis and nine proteins ( $p$-GSK $3 \beta$, BAK1, $p$-P44/42 MAPK, calpastatin, c-IAP2, calpain 2, CDC2, E-cadherin, and P27) were found to be correlated with relapse-free and overall survival (Supplemental Tables S4 and S5) in H. pylori-seropositive gastric cancer patients.
In multivariate analyses, five of these proteins and lymph node metastasis were independent prognostic factors for poor relapse-free and overall survival in $H$. pylori-seropositive gastric cancer patients, including BAK1 (relapsefree survival: HR, $0.453 ; 95 \% \mathrm{CI}, 0.286-0.718 ; P=0.001$; overall survival: HR, 0.476; 95\% CI, 0.305-0.743; $P=0.001$ ), calpastatin (relapse-free survival: HR, 0.480; 95\% CI, 0.307-0.749; $P=0.001$; overall survival: HR, 0.531; 95\% CI, 0.348-0.811; $P=0.003$ ), and lymph node metastasis (relapse-free survival: HR, 1.938; 95\% CI, 1.287-2.918; $P=0.002$; overall survival: HR, 1.748; 95\% CI, 1.202-2.544; $P=0.003$ ).

In contrast to $H$. pylori-seropositive gastric cancer patients, univariate analyses showed lymph node metastasis, distant metastasis, and TNM stage; five proteins ( $p$-GSK $3 \beta$, p-P38 MAPK, DACH1, c-IAP2, and DPYD) correlated with poor relapse-free and overall survival in $H$. pyloriseronegative gastric cancer patients (Supplemental Tables S6 and S7). In multivariate analyses, DACH1 (relapsefree survival: HR, 0.186; 95\% CI, 0.077-0.446; $P<0.001$; overall survival: HR, 0.177; 95\% CI, 0.072-0.436; $P<0.001$ ), lymph node metastasis (relapse-free survival: HR, 1.445; 95\% CI, 0.865-2.413; $P=0.016$; overall survival: HR, 1.405; 95\% CI, 0.835-2.365; $P=0.020)$, and distant metastasis (relapse-free survival: HR, 17.429; 95\% CI, 3.822-79.484; $P<0.001$; overall survival: HR, 15.527; 95\% CI, 3.341-72.157; $P<0.001)$ were independent prognostic factors for poor relapse-free and overall survival in $H$. pylori-seronegative gastric cancer patients.

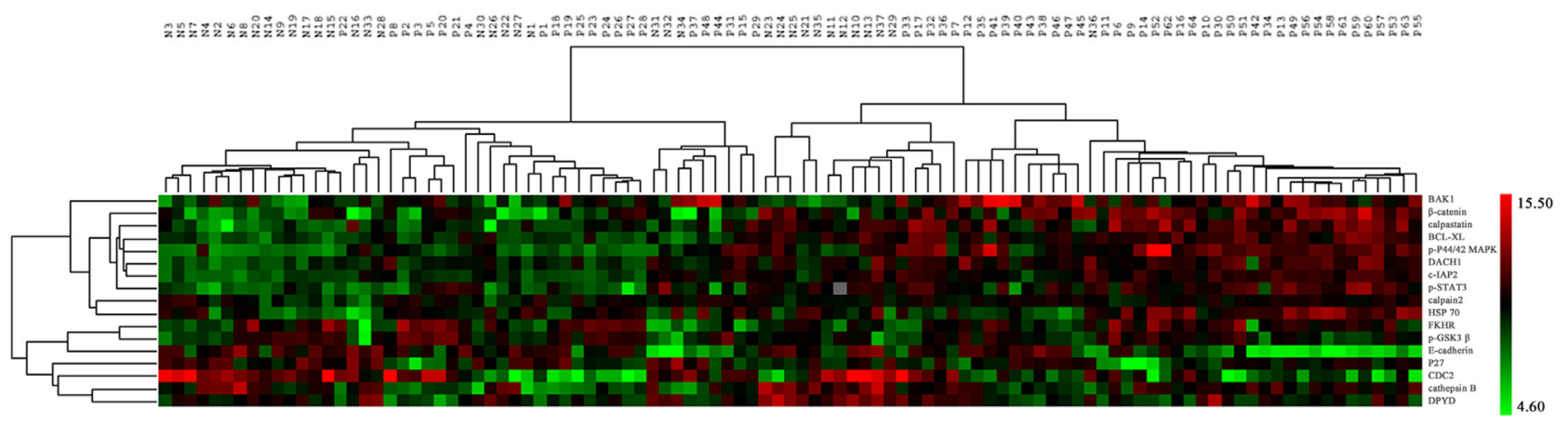

Figure 2 Hierarchical clustering analysis of differentially expressed proteins in $H$. pylori seropositive and seronegative gastric cancer. The color scale showed the level of expression. Red indicates overexpression; green, underexpression; black, no change; and gray, no expression. The number in each column represents the sample number. Each row represents a protein. 
A

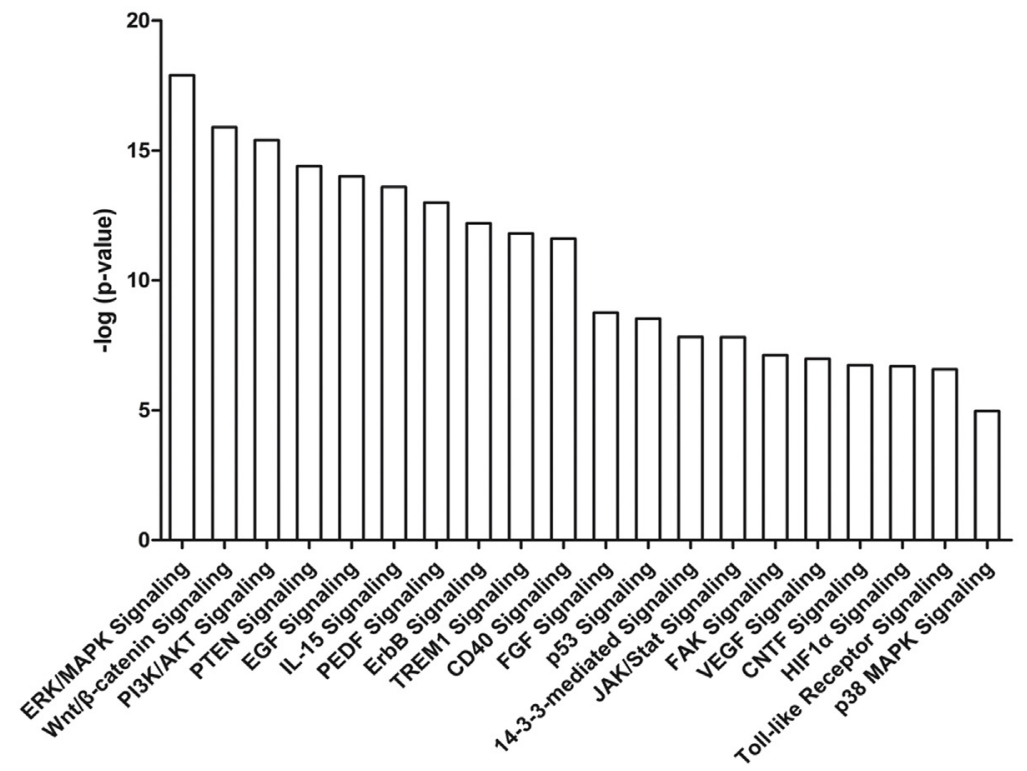

B
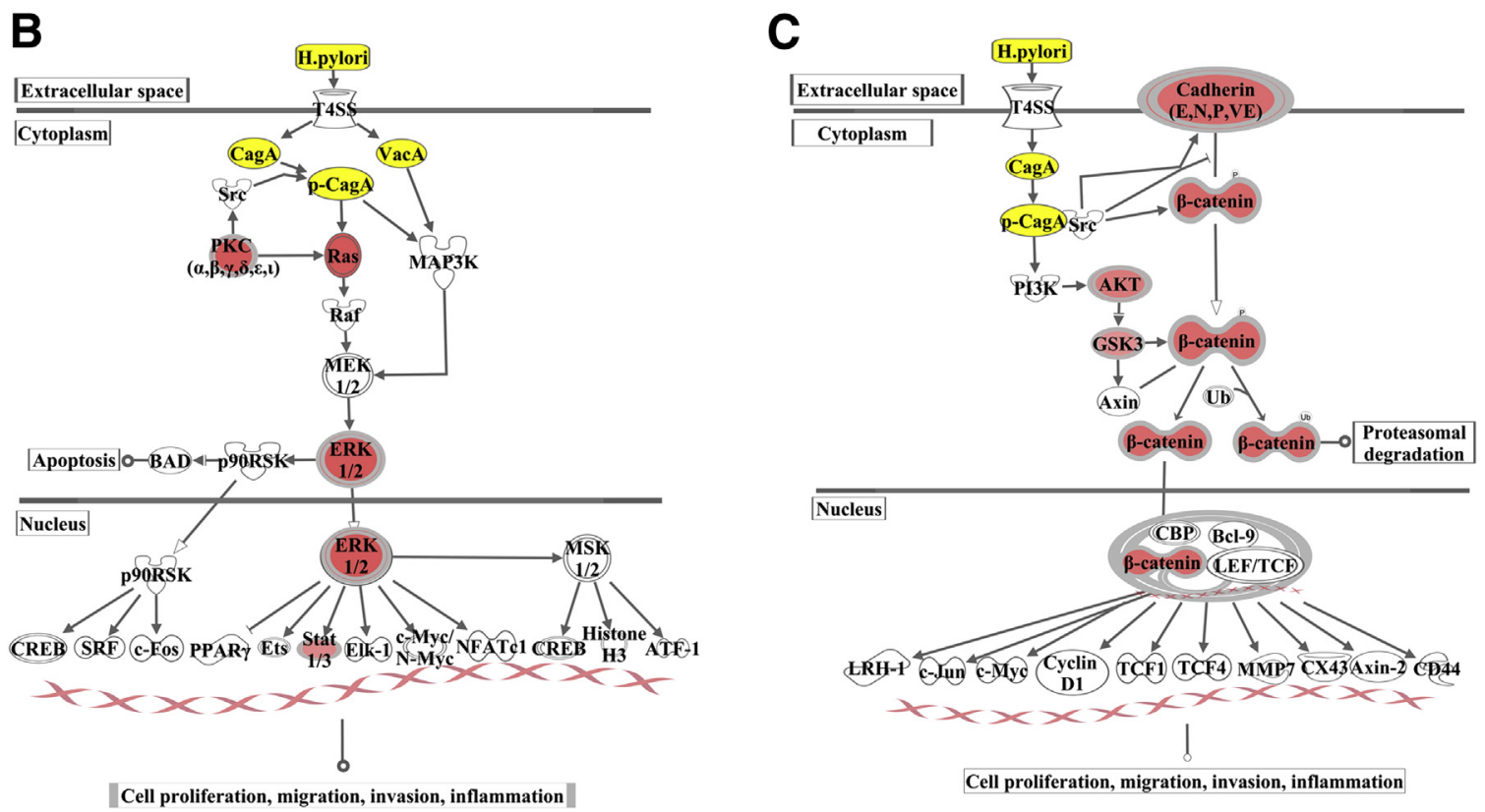

Figure 3 Canonical pathways involved in H. pylori-associated gastric cancer predicted by IPA analysis. A: Top 20 pathways involved in H. pyloriassociated gastric cancer. The $-\log P$ value indicates the significance of the signaling pathways on the basis of the number of differentially expressed proteins involved. ERK/MAPK (B) and $\beta$-catenin (C) pathways are involved in $H$. pylori-associated gastric cancer. Red, up-regulation; yellow, $H$. pylori and its cytotoxin; and $p$, phosphorylation. CNTF, ciliary neurotrophic factor; EGF, endothelial growth factor; ErbB, epidermal growth factor receptor; FAK, focal adhesion kinase; FGF, fibroblast growth factor; HIF, hypoxia-inducible factor; JAK, janus kinase; LEF, lymphoid enhancer-binding factor; MEK, mitogen-activated protein kinase/ extracellular signal-regulated protein kinase; MSK, mitogen- and stress-activated protein kinase; PEDF, pigment epithelium derived factor; PI3K, phosphatidylinositol 3-kinase; PPAR, peroxisome proliferator-activated receptor; PTEN, phosphatase and tensin homolog; TCF, T cell factor; TREM, triggering receptor expressed on myeloid cells.

\section{Establishment of Risk Model for Predicting Gastric Cancer Patient Prognosis}

To improve the prognostic capability, a risk score was calculated on the basis of expression level of BAK1, calpastatin, and $\mathrm{DACH} 1$, as well as corresponding regression coefficients in two groups. The risk score for each gastric cancer was calculated using the following formula:

$$
\text { Risk Score }=H_{l} \times X_{1}+H_{2} \times X_{2}+\ldots+H_{p} \times X_{p},
$$

where $X_{1} \ldots X_{p}$ were the independent variables and $H_{1} \ldots H_{p}$ were their hazard ratios, which were determined by multivariate Cox regression analysis. $^{22}$ In the previously described formula, we applied the reciprocal of the protective factor (ie, BAK1, calpastatin, and DACH1) and converted the hazard factor (ie, lymph node and distant 

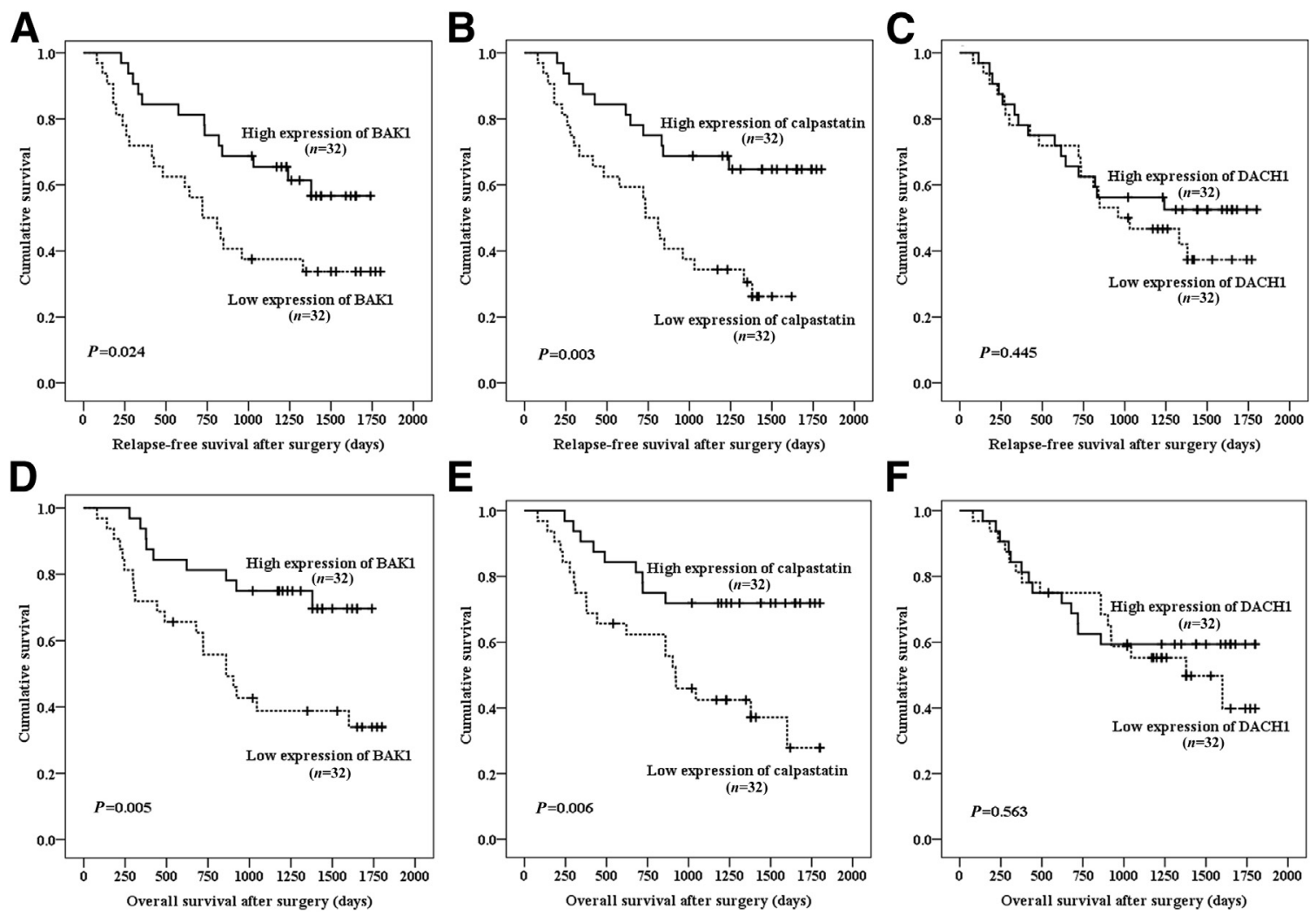

E
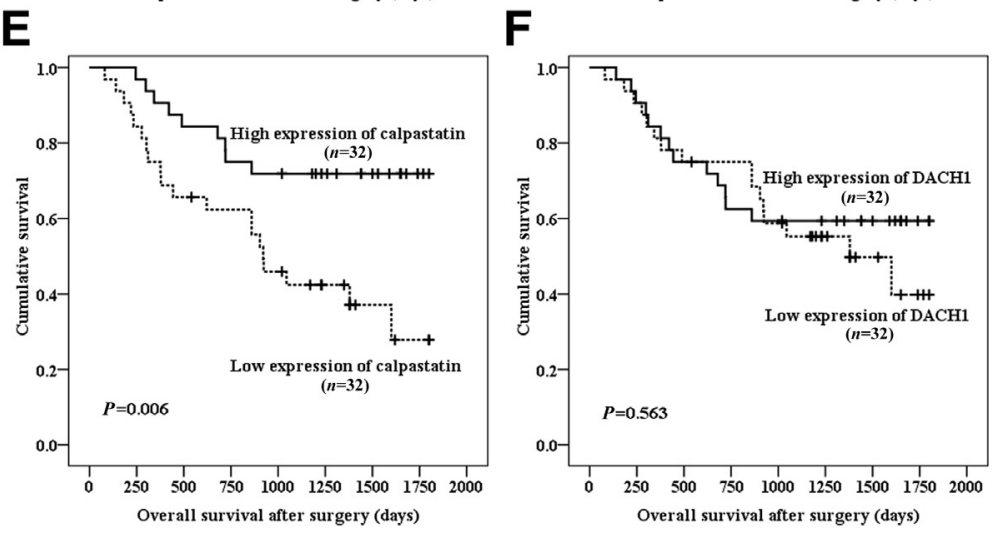

Figure 4 Kaplan-Meier analysis of the relapse-free survival $(\mathbf{A}-\mathbf{C})$ and overall survival $(\mathbf{D}-\mathbf{F})$ of $H$. pylori-seropositive gastric cancer patients, according to the expression level of BAK1 (A and $\mathbf{D})$, calpastatin (B and $\mathbf{E})$, and DACH1 (C and $\mathbf{F})$.

metastasis) to a negative value. For this study, the risk score formulas were as follows:

$$
\begin{aligned}
& \text { Relapse-free survival prognosis model in } H . \text { pylori } \\
& \quad \text { seropositive gastric cancer patients }=[-1.938 \times(\mathrm{LMV}) \\
& +2.208 \times(\mathrm{BAK} 1)+2.083 \times(\text { calpastatin })]
\end{aligned}
$$

Overall survival prognosis model in $H$. pylori seropositive gastric cancer patients $=[-1.748 \times(\mathrm{LMV})$

$+2.101 \times(\mathrm{BAK} 1)+1.883 \times($ calpastatin $)] ;$

Relapse-free survival prognosis model in $H$. pylori seronegative gastric cancer patients $=[-1.445 \times(\mathrm{LMV})$ $-17.429 \times(\mathrm{DMV})+5.376 \times(\mathrm{DACH} 1)] ;$

Overall survival prognosis model in $H$. pylori seronegative gastric cancer patients $=[-1.405 \times(\mathrm{LMV})$

$-15.527 \times(\mathrm{DMV})+5.650 \times(\mathrm{DACH} 1)]$.

where LMV represents lymph node metastasis and DMV represents distant metastasis. According to the previously described formulas, we performed Kaplan-Meier and log-rank survival analysis and our data suggest that the risk model could stratify patients more accurately than any one of them $(P=0.000)$ (Figure 6). Overall, the
H. pylori-seropositive group had a better prognosis (relapse-free and overall survival).

\section{Discussion}

The epidemiological studies and our data suggested that positive $H$. pylori serological status is associated with favorable relapse-free survival and overall survival in patients with gastric adenocarcinoma after curative resection, which suggests different carcinogenic processes exist in two groups of gastric cancer patients. However, the mechanism that $H$. pylori-seropositive status contributes to better prognosis remains unclear. Also, we found both BAK1 and calpastatin are independent beneficial prognostic factors in gastric cancer patients seropositive for $H$. pylori, and $\mathrm{DACH} 1$ is an independent beneficial prognostic factor in gastric cancer patients seronegative for $H$. pylori. Our PPA and IPA data suggest that many signaling pathways, such as the MAPK pathway and the $\beta$-catenin pathway, are dysregulated differently between $H$. pylori seropositive and seronegative groups, which may involve carcinogenesis and explain the different prognosis.

Through PPA analysis, 17 proteins were found to be differentially expressed in gastric cancer tissues between patients seropositive and seronegative for $H$. pylori. Most of these differentially expressed proteins are important in cancer 
A

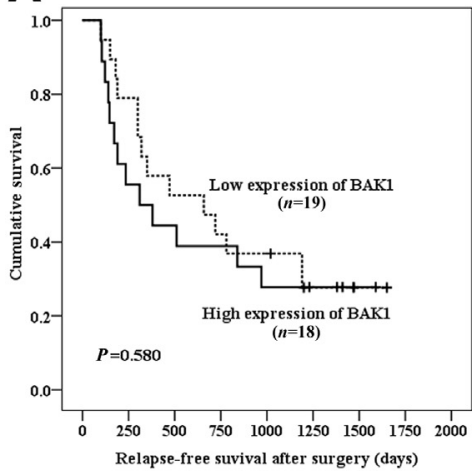

D

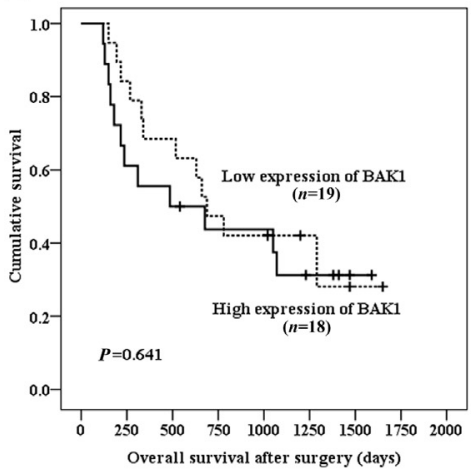

B

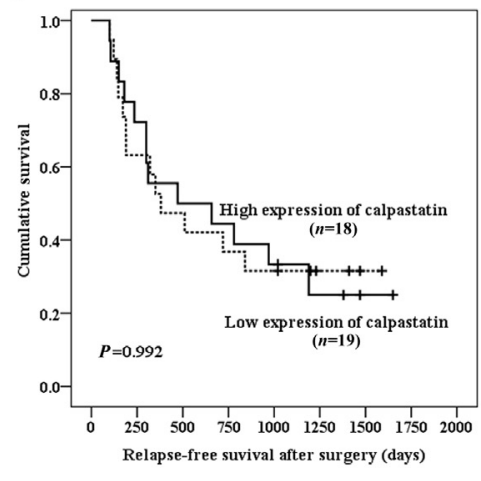

$\mathbf{E}$

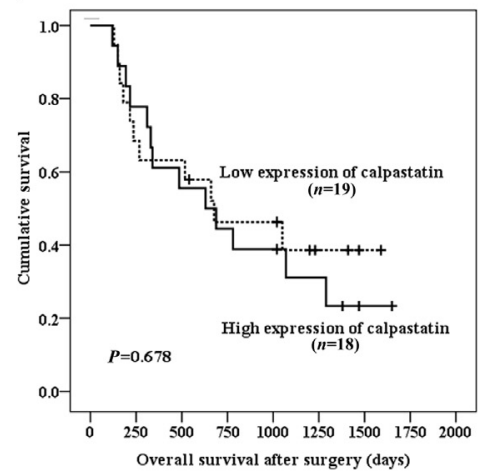

C

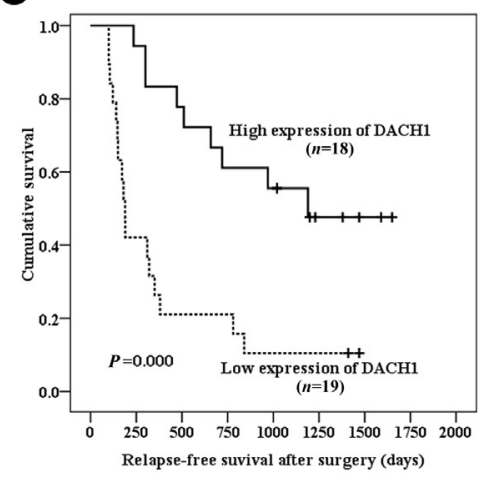

$\mathbf{F}$

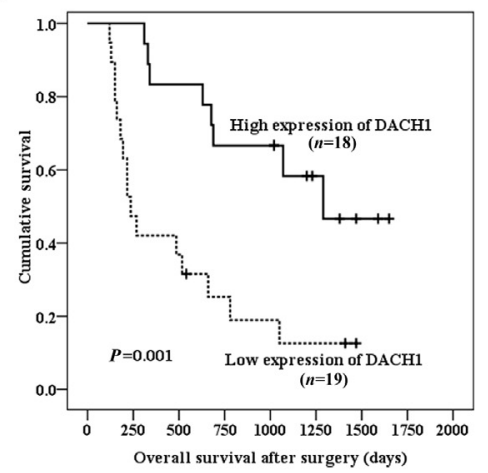

Figure 5 Kaplan-Meier analysis of the relapse-free survival $(\mathbf{A}-\mathbf{C})$ and overall survival $(\mathbf{D}-\mathbf{F})$ of $H$. pylori-seronegative gastric cancer patients, according to the expression level of BAK1 ( $\mathbf{A}$ and $\mathbf{D})$, calpastatin (B and $\mathbf{E})$, and DACH1 (C and $\mathbf{F})$.

signaling, including cell adhesion, proliferation, migration, invasion, apoptosis, and cell cycle regulation. Dysregulated expression of some of these proteins, such as $\beta$-catenin, $p$-GSK $3 \beta$, TGF- $\beta$, STAT3, and DPYD, has been reported in gastric cancer in previous studies, which were consistent with our findings. However, to our knowledge, the association of these proteins in gastric cancer with $H$. pylori infection has not been reported. We also identified several novel proteins in gastric cancer, such as DACH1, BAK1, and calpastatin, which are associated with different prognostic values in the context of $H$. pylori serological status. Furthermore, the existence of difference in protein expression and canonical pathways identified by IPA between these two groups strongly supports the notion of a different underlying tumorigenesis mechanism associated with $H$. pylori infection.

In the patients seropositive for $H$. pylori, the expression of protein BAK1 (BCL-2 homologous antagonist/killer) in cancer tissues was up-regulated compared with patients seronegative for $H$. pylori. BAK1 is involved in initiating apoptosis, which is a pro-apoptotic member of the BCL-2 family. Overexpression of BAK1 could induce apoptosis in gastric cancer cell lines. ${ }^{25}$ Two models of BAK1 activation have been proposed: $H$. pylori infection could activate the pro-apoptotic Bcl-2-homology-3-only proteins (ie, big brain, BCL2-like 11, p53 upregulated modulator of apoptosis, phorbol 12-myristate 13-acetate induced protein 1, Bcl-XL/Bcl-2-associated death promoter, Bcl2 modifying factor, harakiri, and Bcl-2-interacting killer) through a mitochondrial pathway, which then directly binds and activates $\mathrm{BAX}$ and $\mathrm{BAK} 1$, or $\mathrm{BH} 3$-only proteins may bind to the prosurvival BCL-2-like proteins (ie, BCL-2, BCL-xL, and BCL-w) to indirectly activate BAX and BAK1. Once
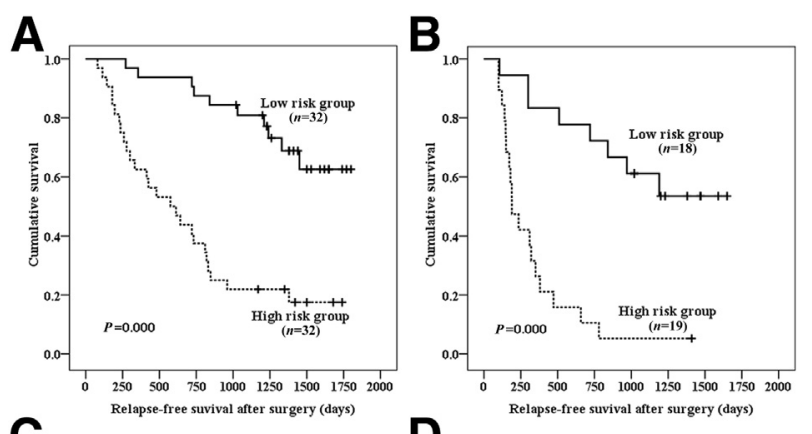

C
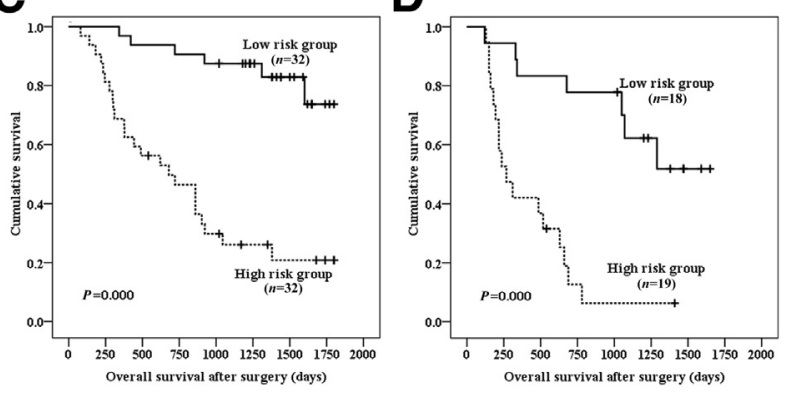

Figure 6 Kaplan-Meier analysis of relapse-free survival (A and $\mathbf{B})$ and overall survival ( $\mathbf{C}$ and $\mathbf{D}$ ) on the basis of risk models. The high-risk scores predict unfavorable survival in $\mathrm{H}$. pylori-seropositive gastric cancer patients ( $\mathbf{A}$ and $\mathbf{C})$ and seronegative gastric cancer patients ( $\mathbf{B}$ and $\mathbf{D})$. 
activated, BAX and BAK1 oligomerize to form pores in the mitochondrial outer membrane that releases cytochrome $c$. Increase of cytosolic cytochrome $c$ leads to caspase activation and subsequent cell death. ${ }^{26,27} \mathrm{H}$. pylori may also activate proinflammatory cytokines, such as tumor necrosis factor- $\alpha$, FasL, and tumor necrosis factor-related apoptosisinducing ligand. ${ }^{28-31}$ These death ligands bind to cell surface receptors, resulting in the activation of caspase- 8 . Activated caspase- 8 can either activate downstream caspases directly or engage the previously described pathway via a cleaved form of the BH3-only protein BID. Therefore, increased expression of BAK1 in tumor tissues, which enhances cancer cell apoptosis, could explain the favorable prognosis in the patients with previous $H$. pylori infection.

The calpain system, including $\mathrm{Ca}^{2+}$-dependent proteases $\mu$-calpain and m-calpain and their endogenous inhibitor calpastatin, has been implicated in cancer progression and response to therapy in several studies. In recent studies, a high level of calpain expression is of clear adverse effect on cancer patients. Calpains degrade tumor suppressors, such as p53 or the $N F 2$ gene product Merlin, ${ }^{32,33}$ and cleave I $\mathrm{B} \alpha$ at a specific proline-glutamate-serine-threonine rich sequence, allowing NF$\kappa \mathrm{B}$ translocation into the nucleus and, thus, promoting cell survival. ${ }^{34}$ Calpains are also essential for cytoskeleton reorganization and, therefore, they promote cell migration and invasion. ${ }^{35}$ Moreover, calpains are essential for vascular endothelial growth factor response and angiogenesis and may, therefore, promote tumor vascularization. ${ }^{36}$ Recent in vitro evidence has suggested that calpain activity after cisplatin treatment influences the apoptotic process by reducing P73, which acts as a pro-apoptotic factor. ${ }^{37}$ Also, knockdown of calpastatin reduces the chemosensitivity in gastric cancer cell lines through regulation of the thymidylate synthase-5-fluorodeoxyuridine monophsophate level. ${ }^{38}$ In our present study, calpastatin was overexpressed in gastric cancer tissues in patients seropositive for $H$. pylori compared with patients who are seronegative. However, further study is necessary to determine its role in tumorigenesis of gastric cancer.

The tumor-suppressor gene $D A C H 1$, widely expressed in the epithelial cells, regulates gene expression either as a coactivator or through direct binding to DNA. ${ }^{39}$ The reduced DACH1 expression (probably through DNA methylation) predicts poor outcome in breast cancer and gastric cancer. ${ }^{40}$ The C-terminal of DACH1 binds P53 to inhibit colony formation and induce cell cycle arrest in lung adenocarcinoma cells. Re-introduction of DACH1 into breast cancer cell inhibits tumor initiation and metastasis in vivo. ${ }^{41,42}$ Also, DACH1 suppresses cell growth by reactivating TGF- $\beta$ signaling in hepatocellular carcinoma. ${ }^{43}$ In our study, we found both DACH1 and TGF- $\beta$ expression levels were decreased in tumor tissues in patients seropositive for $H$. pylori; in addition, the patients with a high level of expression of DACH1 have a better prognosis than those with a low expression, which is consistent with previous reports.

Combining previous reports and our own data, it is clear that gastric cancer should be separated into two groups on the basis of $H$. pylori infection status because patients with positive $H$. pylori serological test results had a favorable prognosis. It is also clear that the underlying tumorigenesis mechanism is different in these two groups of patients. To understand these differences is clinically important because H. pylori-seronegative patients should be treated more aggressively and follow-up programs should be directed to improve the clinical outcome. In addition, the risk model developed in this study on the basis of the protein expression and other clinical parameters (ie, metastasis to lymph node) could be helpful in stratifying gastric cancer patients for more appropriate treatment, although additional study to confirm this finding is needed.

\section{Acknowledgments}

We thank the technical support of the Tissue Bank of the First Hospital of Jilin University in preparation of protein, Dr. Weijia Zhang for his statistical support, and Dr. Aimee Lucas and Mark Hall for review and revision of the manuscript.

D.Y.Z., J.S., and F.Y. contributed equally in conceiving the hypothesis and overall study design; G.L., D.Y.Z., and F.Y. participated in the experimental design; Z.W., X.L., and W.L. assisted in performing the PPA assay; L.W. and Q.W. assisted in collection of the clinical data; G.L. and C.W. were involved in statistical analysis; G.L. and F.Y. were involved in summarizing the final data; and G.L., D.Y.Z., and F.Y. contributed to the preparation of the manuscript.

\section{Supplemental Data}

Supplemental material for this article can be found at http://dx.doi.org/10.1016/j.ajpath.2014.01.027.

\section{References}

1. Zur Hausen H: The search for infectious causes of human cancers: where and why. Virology 2009, 392:1-10

2. Parkin DM, Bray F, Ferlay J, Pisani P: Global cancer statistics, 2002. CA Cancer J Clin 2005, 55:74-108

3. Pinchuk IV, Morris KT, Nofchissey RA, Earley RB, Wu JY, Ma TY, Beswick EJ: Stromal cells induce Th17 during Helicobacter pylori infection and in the gastric tumor microenvironment. PLoS One 2013, 8:e53798

4. Fox JG, Wang TC: Inflammation, atrophy, and gastric cancer. J Clin Invest 2007, 117:60-69

5. Parkin DM: Global cancer statistics in the year 2000. Lancet Oncol 2001, 2:533-543

6. Bray F, Ferlay J, Pisani P, Parkin DM: GLOBOCAN 2002: Cancer Incidence, Mortality and Prevalence Worldwide, IARC CancerBase No. 5 Version 2.0. Lyon, IARC Press, 2004

7. Malfertheiner P, Sipponen P, Naumann M, Moayyedi P, Megraud F, Xiao SD, Sugano K, Nyren O: Helicobacter pylori eradication has the potential to prevent gastric cancer: a state-of-the-art critique. Am J Gastroenterol 2005, 100:2100-2115

8. Stein RA: Epigenetics: the link between infectious diseases and cancer. JAMA 2011, 305:1484-1485 
9. Schistosomes, liver flukes and Helicobacter pylori: IARC Working Group on the Evaluation of Carcinogenic Risks to Humans. Lyon, 7-14 June 1994. IARC Monogr Eval Carcinog Risks Hum 1994, 61:1-241

10. Lee WJ, Lin JT, Shun CT, Lee WC, Yu SC, Lee PH, Chang KJ, Wei TC, Chen KM: Comparison between resectable gastric adenocarcinomas seropositive and seronegative for Helicobacter pylori. Br J Surg 1995, 82:802-805

11. Meimarakis G, Winter H, Assmann I, Kopp R, Lehn N, Kist M, Stolte M, Jauch KW, Hatz RA: Helicobacter pylori as a prognostic indicator after curative resection of gastric carcinoma: a prospective study. Lancet Oncol 2006, 7:211-222

12. Marrelli D, Pedrazzani C, Berardi A, Corso G, Neri A, Garosi L, Vindigni C, Santucci A, Figura N, Roviello F: Negative Helicobacter pylori status is associated with poor prognosis in patients with gastric cancer. Cancer 2009, 115:2071-2080

13. Kang SY, Han JH, Ahn MS, Lee HW, Jeong SH, Park JS, Cho YK, Han SU, Kim YB, Kim JH, Sheen SS, Lim HY, Choi JH: Helicobacter pylori infection as an independent prognostic factor for locally advanced gastric cancer patients treated with adjuvant chemotherapy after curative resection. Int J Cancer 2012, 130:948-958

14. Ohnishi N, Yuasa H, Tanaka S, Sawa H, Miura M, Matsui A, Higashi H, Musashi M, Iwabuchi K, Suzuki M, Yamada G, Azuma T, Hatakeyama M: Transgenic expression of Helicobacter pylori CagA induces gastrointestinal and hematopoietic neoplasms in mouse. Proc Natl Acad Sci U S A 2008, 105:1003-1008

15. Preston-Martin S, Pike MC, Ross RK, Jones PA, Henderson BE: Increased cell division as a cause of human cancer. Cancer Res 1990 50:7415-7421

16. Cho SO, Kim KH, Kim H: Extracellular signal-regulated kinase induces phosphorylation of IkappaBalpha in Helicobacter pyloriinfected gastric epithelial AGS cells. Inflammopharmacology 2007, $15: 26-30$

17. Cao X, Tsukamoto T, Nozaki K, Tanaka H, Cao L, Toyoda T, Takasu S, Ban H, Kumagai T, Tatematsu M: Severity of gastritis determines glandular stomach carcinogenesis in Helicobacter pyloriinfected Mongolian gerbils. Cancer Sci 2007, 98:478-483

18. Kim SS, Ruiz VE, Carroll JD, Moss SF: Helicobacter pylori in the pathogenesis of gastric cancer and gastric lymphoma. Cancer Lett 2011, 305:228-238

19. Chiba T, Marusawa H: A novel mechanism for inflammationassociated carcinogenesis: an important role of activation-induced cytidine deaminase (AID) in mutation induction. J Mol Med (Berl) 2009, 87:1023-1027

20. Zhang DY, Ye F, Gao L, Liu X, Zhao X, Che Y, Wang H, Wang L, Wu J, Song D, Liu W, Xu H, Jiang B, Zhang W, Wang J, Lee P: Proteomics, pathway array and signaling network-based medicine in cancer. Cell Div 2009, 4:20

21. Edge S, Byrd DR, Compton CC, Fritz AG, Greene FL, Trotti A (Eds): AJCC Cancer Staging Manual. ed 7. New York, Springer, 2011.

22. Wang D, Ye F, Sun Y, Li W, Liu H, Jiang J, Zhang Y, Liu C, Tong W, Gao L, Zhang W, Seetoe T, Lee P, Suo J, Zhang DY: Protein signatures for classification and prognosis of gastric cancer a signaling pathway-based approach. Am J Pathol 2011, 179: $1657-1666$

23. Ye F, Che Y, McMillen E, Gorski J, Brodman D, Saw D, Jiang B, Zhang DY: The effect of Scutellaria baicalensis on the signaling network in hepatocellular carcinoma cells. Nutr Cancer 2009, 61:530-537

24. Ekstrom AM, Held M, Hansson LE, Engstrand L, Nyren O: Helicobacter pylori in gastric cancer established by CagA immunoblot as a marker of past infection. Gastroenterology 2001, 121:784-791

25. Sun XP, Zhang X, He C, Qiao H, Jiang X, Jiang H, Sun X: ABT737 synergizes with arsenic trioxide to induce apoptosis of gastric carcinoma cells in vitro and in vivo. J Int Med Res 2012, 40: $1251-1264$

26. O'Neill JW, Manion MK, Maguire B, Hockenbery DM: BCL-XL dimerization by three-dimensional domain swapping. J Mol Biol 2006, 356:367-381
27. Westphal D, Dewson G, Czabotar PE, Kluck RM: Molecular biology of Bax and BAK1 activation and action. Biochim Biophys Acta 2011, 1813:521-531

28. Li K, Dan Z, Hu X, Ouzhu M, Ciren Y, Wang Z, Wang J, Yang X, Ze Y: CD14 overexpression upregulates TNF-alpha-mediated inflammatory responses and suppresses the malignancy of gastric carcinoma cells. Mol Cell Biochem 2013, 376:137-143

29. Gray BM, Fontaine CA, Poe SA, Eaton KA: Complex T cell interactions contribute to Helicobacter pylori gastritis in mice. Infect Immun 2013, 81:740-752

30. Kotlowska-Kmiec A, Bakowska A, Szarszewski A, Kaminska B, Luczak G, Radys W, Landowski P, Brodzicki J, Korzon M, Liberek A: Helicobacter pylori increases expression of proapoptotic markers Fas and FasL on CD4 lymphocytes in children. Acta Biochim Pol 2009, $56: 433-438$

31. Martin JH, Potthoff A, Ledig S, Cornberg M, Jandl O, Manns MP, Kubicka S, Flemming P, Athmann C, Beil W, Wagner S: Effect of H. pylori on the expression of TRAIL, FasL and their receptor subtypes in human gastric epithelial cells and their role in apoptosis. Helicobacter 2004, 9:371-386

32. Kimura Y, Koga H, Araki N, Mugita N, Fujita N, Takeshima H, Nishi T, Yamashima T, Saido TC, Yamasaki T, Moritake K, Saya H, Nakao M: The involvement of calpain-dependent proteolysis of the tumor suppressor NF2 (merlin) in schwannomas and meningiomas. Nat Med 1998, 4:915-922

33. Kubbutat MH, Vousden KH: Proteolytic cleavage of human p53 by calpain: a potential regulator of protein stability. Mol Cell Biol 1997, $17: 460-468$

34. Han Y, Weinman S, Boldogh I, Walker RK, Brasier AR: Tumor necrosis factor-alpha-inducible IkappaBalpha proteolysis mediated by cytosolic m-calpain: a mechanism parallel to the ubiquitin-proteasome pathway for nuclear factor-kappab activation. J Biol Chem 1999, 274: 787-794

35. Potter DA, Tirnauer JS, Janssen R, Croall DE, Hughes CN, Fiacco KA, Mier JW, Maki M, Herman IM: Calpain regulates actin remodeling during cell spreading. J Cell Biol 1998, 141:647-662

36. Su Y, Cui Z, Li Z, Block ER: Calpain-2 regulation of VEGF-mediated angiogenesis. FASEB J 2006, 20:1443-1451

37. Al-Bahlani S, Fraser M, Wong AY, Sayan BS, Bergeron R, Melino G, Tsang BK: P73 regulates cisplatin-induced apoptosis in ovarian cancer cells via a calcium/calpain-dependent mechanism. Oncogene 2011, 30: 4219-4230

38. Nabeya Y, Suzuki T, Furuya A, Koide N, Ohkoshi M, Takiguchi M, Ochiai T, Matsubara H, Hiwasa T: Calpain regulates thymidylate synthase-5-fluoro-dUMP complex levels associated with response to 5fluorouracil in gastric cancer cells. Cancer Sci 2011, 102:1509-1515

39. Popov VM, Wu K, Zhou J, Powell MJ, Mardon G, Wang C, Pestell RG: The Dachshund gene in development and hormoneresponsive tumorigenesis. Trends Endocrinol Metab 2010, 21:41-49

40. Yamada Y, Arao T, Gotoda T, Taniguchi H, Oda I, Shirao K, Shimada Y, Hamaguchi T, Kato K, Hamano T, Koizumi F, Tamura T, Saito D, Shimoda T, Saka M, Fukagawa T, Katai H, Sano T, Sasako M, Nishio K: Identification of prognostic biomarkers in gastric cancer using endoscopic biopsy samples. Cancer Sci 2008, 99:2193-2199

41. Chen K, Wu K, Cai S, Zhang W, Zhou J, Wang J, Ertel A, Li Z, Rui H, Quong A, Lisanti MP, Tozeren A, Tanes C, Addya S, Gormley M, Wang C, McMahon SB, Pestell RG: Dachshund binds p53 to block the growth of lung adenocarcinoma cells. Cancer Res 2013, 73: 3262-3274

42. Wu K, Katiyar S, Li A, Liu M, Ju X, Popov VM, Jiao X, Lisanti MP, Casola A, Pestell RG: Dachshund inhibits oncogene-induced breast cancer cellular migration and invasion through suppression of interleukin-8. Proc Natl Acad Sci U S A 2008, 105:6924-6929

43. Zhu H, Wu K, Yan W, Hu L, Yuan J, Dong Y, Li Y, Jing K, Yang Y, Guo M: Epigenetic silencing of DACH1 induces loss of transforming growth factor-beta1 antiproliferative response in human hepatocellular carcinoma. Hepatology 2013, 58:2012-2022 